Revista Venezolana de Gerencia (RVG)

Año 16. $\mathrm{N}^{\circ}$ 54, 2011, 323 - 325

Universidad del Zulia (LUZ) • ISSN 1315-9984

\title{
El arte de tomar decisiones con contenidos éticos
}

"El último objetivo de la actividad económica es ético: el bien del hombre"

De Garay, 1997

\section{Díaz Bermúdez, José Félix*}

La toma de decisiones personales o gerenciales no debe ser vista únicamente como un proceso organizado, estructurado por etapas, que comprende inicialmente el diagnóstico de la situación específica y la conformación de una serie de alternativas a través de las cuales se implemente una decisión, atendiendo a las reglas del menos costo o de la resolución más fácil. La toma de decisiones implica no solamente un asunto de secuencias técnicas inspirado por la lógica sino una compleja y exigente determinación con contenidos éticos ${ }^{1}$.
La apreciación del principio de: "coste-beneficios" y la obtención de una particular: "utilidad" constituye una guía para la apreciación de ciertos elementos particularmente asociados a aspectos económicos, que si bien no son descartables, no son los únicos a considerar. Inclusive el consejo ofrecido por las corrientes economicistas de expresar en términos monetarios el impacto de la decisión cuando ella en esencia no tenga estricto carácter dinerario, ofrece una prioridad que no siempre pudiera ser la más acertada.

* Abogado egresado de la UCV, especialista en derecho del trabajo y seguridad social, egresado de la Universidad de Paris II. Ex profesor de la Universidad Central de Venezuela, UCAB y Unimet en materias jurídicas. Ha ocupado posiciones gerenciales, consultoras y asesoras en importantes organizaciones privadas y públicas entre ellas Corpoven, S.A., La Electricidad de Caracas, Torres, Plaz \& Araujo, Pequiven, S.A., entre otras. Es autor de libros, estudios e investigaciones de tipo jurídico e histórico. Es colaborador de la "Revista Américas" de la OEA y del diario "El Universal" de Caracas, entre otras publicaciones.

1 "La ética empresarial se refiere a cómo una compañía integra el conjunto de valores (honestidad, confianza, respeto, justicia y otros) en sus propias políticas, prácticas y en la toma de decisiones en todos los niveles de la empresa. Adicionalmente, la ética empresarial implica comportarse de acuerdo a los estándares legales, además de su adherencia a las leyes y regulaciones internas". "STAKEHOLDERS" Año 1 - №. 1, Lima, Perú. 
El arte de tomar decisiones con contenidos éticos

Díaz Bermúdez, José Félix

En lo personal, las decisiones han sido evaluadas como una serie de informaciones, conocimientos y resoluciones racionales de un sujeto que se vincula en razón a las decisiones que ocupa con las metas, objetivos y criterios de una empresa u organización. Formalmente la gran mayoría de ellas expresa entre sus principios y valores una serie de principios de contenido moral y ético que, en teoría, forman parte de las reglas de conducta de la organización. Sin embargo, muchas de las decisiones que se adoptan en organismos, instituciones y empresas donde los componentes gerenciales son débiles y se admiten situaciones subjetivas, despliegue de intereses, confrontaciones de poder, ambiciones y desquites, parecieran prescindir de consideraciones verdaderamente éticas en las decisiones.

La forma de pensar los negocios, acordar sus contenidos y tomar determinaciones que comprometen la acción individual del gerente y el nombre y prestigio de la organización, institución o empresa que se representa, adquiere connotaciones distintas mucho más integrales de acuerdo a los principios, reglas y orientaciones de la Responsabilidad Social Empresarial.
Numerosos autores de la novedosa materia nos advierten de la trascendencia que el enfoque ético recobra:

"Está en nuestra capacidad de discutir de lo que es justo donde nace la posibilidad de una organización política justa", afirman los autores franceses Postel y Rousseau, y de la misma manera nos observan que: "El capitalismo requiere la elaboración de una forma de compromiso entre la ética y la eficacia, entre la economía y la justicia social"2.

Por su parte, Warren Bennis ${ }^{3}$ ha expresado que: "La integridad es una virtud que hace que un directivo empiece a ser líder". En igual sentido, Carlos María Moreno Pérez ${ }^{4}$ ha señalado que: "Si el equipo directivo no tiene una voluntad decidida por la ética, difícilmente la empresa se moverá en parámetros éticos".

Otro concepto de alto contenido es el que nos ofrece el autor colombiano Álvaro Andrés Hamburger Fernández ${ }^{5}$, quien ha afirmado que: "Una empresa exitosa es aquella en que se respetan los derechos humanos, se acatan los derechos en el trabajo, se protege el medio ambiente y se lucha contra la corrupción".

La literatura más autorizada sobre temas de Responsabilidad Social, desde

2 LA RESPONSABILITE SOCIALE DES ENTREPRISES, UNE PERSPECTIVE INSTITUTIONNALISTE, "Ethique, entreprise etRSE", Nicolas Portel y Sandrine Rousseau, Septentrion Presse Universitaire, Villeneuve d' Ascq, France, 2009, pp. 121 y 125 respectivamente.

3 DIRIGIR PERSONAS ES COMO ADIESTRAR GATOS. SOBRE EL LIDERAZGO, Warren Bennis, Editorial Centro de Estudios Ramón Areces, Madrid, 2000, pág. 51.

4 "EL LIDERAZGO ETICO FUNDAMENTADO EN VIRTUDES", Carlos María Moreno Pérez, Papeles de Ética, Economía y Dirección, Nㅜ 6, 2001.

5 "ETICA Y RESPONSABILIDAD SOCIAL EN LAS EMPRESAS", Álvaro Andrés Hamburger, Management, año XVI, n. ${ }^{\circ}$ 28, julio-diciembre 2007, Colombia, p. 114. 
Bernardo Kliskberg en Argentina con su obra: "RSE un imperativo ético y económico" hasta Víctor Guédez en Venezuela, con su libro: "La ética gerencial: instrumentos estratégicos que facilitan las decisiones correctas", nos ilustran con suficiencia sobre esta exigencia cada vez más prioritaria mediante la cual se asegura la confiabilidad tanto de los gobiernos como de las empresas, en el mundo global que exige cada vez más integridad y compromiso, responsabilidad y respeto con el ser humano y con el medio ambiente.

Es precisamente Víctor Guédez quien nos señala como la decisión y la acción ética deben ser colocadas: "en su justo lugar" y nos presenta interrogantes válidas establecidas en los Modelos de Análisis de Dilemas de Nash y en el Modelo ORAVED, en las que se presentan estas fundamentales precisiones: “¿Cómo definiría el problema si se coloca en el otro lado?... ¿Podría sostener la decisión ante superiores, colegas, amigos y familiares? ...Valores relacionados con cada opción..."6, con todo lo cual nos ayuda a entender el inmenso significado de la decisión ética que se involucra los componentes de la libertad, la responsabilidad y el discernimiento para impulsar la decisión.

La ética representa, aun cuando no el único, uno de los objetivos fundamentales de la Responsabilidad Social Empresarial. En el carácter y contenido de las decisiones se desprende la real o inexistente conformidad con los valores proclamados y la auténtica vigencia de los Códigos de Ética. Unos serán objeto más temprano que tarde de severos cuestionamientos por los errores en sus decisiones y por la falta de compresión de los imperativos de orden jurídico y de orden ético ante la colectividad y ante los individuos en lo interno y en lo externo; otros superarán para prestigio de sus organizaciones la prueba de la confiabilidad, de la coherencia, de la responsabilidad, incorporando el valor agregado de la integridad, junto al de la calidad del producto, oportunidad de respuesta a tiempo, precios competitivos, ahorros de recursos, satisfacción de sus clientes y de la sociedad. La decisión con ética es el arte del gerente virtuoso. 